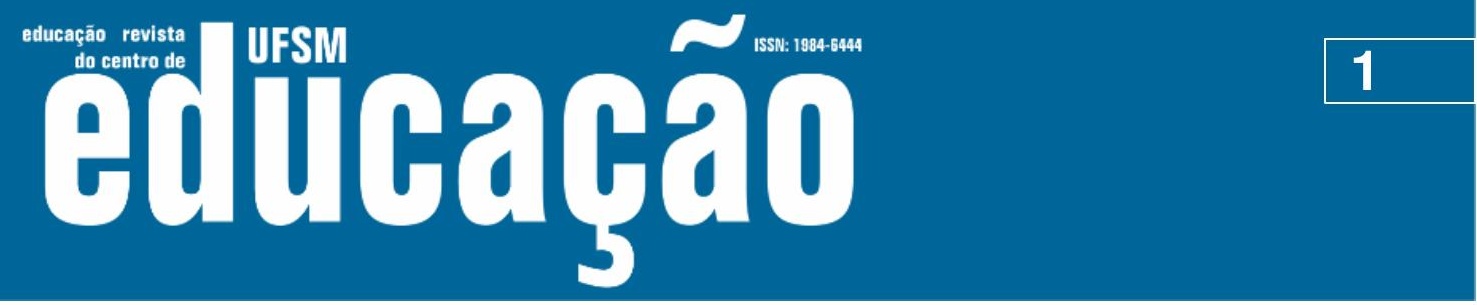

ISSN: 1984-6444 | http://dx.doi.org/10.5902/1984644436820

\title{
Conselhos Escolares na Rede Estadual do Rio de Janeiro: participação ou participacionismo?
}

School Councils in the state network of Rio de Janeiro: participation or participationism?

* Janaina Moreira de Oliveira Goulart

Doutoranda na Universidade Federal do Rio de Janeiro, Rio de Janeiro, Brasil.

janaigtmetro5@gmail.com — https://orcid.org/0000-0002-9218-9933

** Daniela Patti do Amaral

Professora Associada da Universidade Federal do Rio de Janeiro, Rio de Janeiro, Brasil. danielapatti.ufrj@gmail.com

Recebido em 09 de fevereiro de 2019

Aprovado em 21 de maio de 2019

Publicado em 15 de julho de 2019

\section{RESUMO}

A presente discussão se propõe a refletir sobre a participação, na perspectiva da gestão democrática, dos membros dos conselhos escolares no âmbito da rede estadual do Rio Janeiro, partindo das análises dos textos produzidos pela Secretaria de Estado de Educação (SEEDUC/RJ) e dos contextos que influenciaram a instituição dos organismos colegiados nesta rede. $\mathrm{O}$ artigo apresenta um debate sobre o cenário em que foram instituídos os conselhos escolares nas escolas estaduais e, para tanto, analisou-se os textos oficiais que tratam das competências dos membros do órgão. Sublinha-se a ausência do caráter deliberativo deste colegiado conforme determinado pela legislação que o regulamentou. A discussão traz elementos para a reflexão da transformação social por meio da participação dos sujeitos, propondo um processo dialógico e participativo que não dependam exclusivamente de leis, mas que, sobretudo, estejam articulados com os propósitos de se concretizar os ideais de uma sociedade mais justa, partindo de relações mais horizontais. Acreditamos que a ausência do caráter deliberativo poderá interferir nas estratégias de uma gestão democrática, levando a crer que descaracteriza a concepção de participação no seu sentido mais amplo, dando lugar a uma forma mais semelhante de participacionismo. Palavras-chave: Gestão democrática; Conselhos escolares; Participação. 


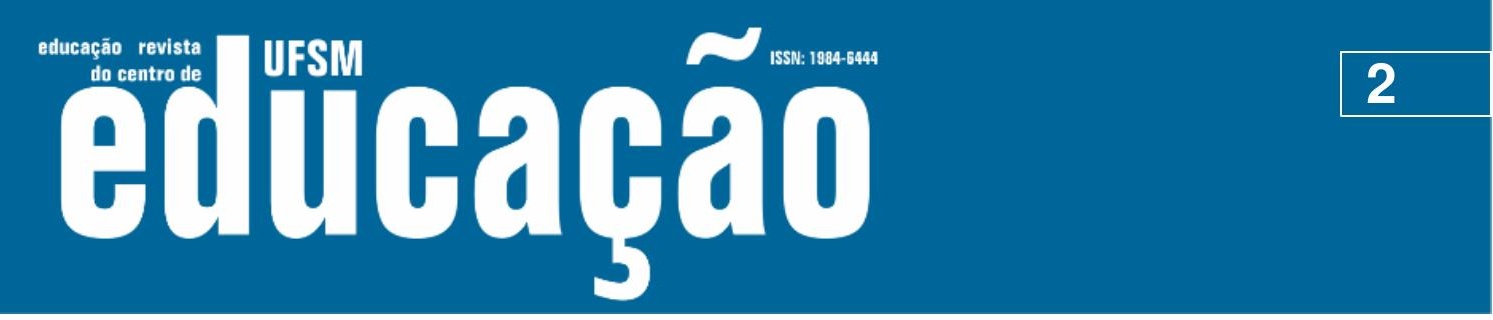

ISSN: 1984-6444 | http://dx.doi.org/10.5902/1984644436820

\section{ABSTRACT}

The present discussion proposes to reflect on the participation, in the perspective of democratic management, of the members of the school councils within the Rio Janeiro state network, based on the analysis of the texts produced by the State Secretariat of Education (SEEDUC/RJ) and the contexts that influenced the institution of the school councils in this network. The article presents a debate about the setting in which the school councils were instituted in the state schools and, for that, the official texts that deal with the competences of the members of the organ were analyzed. The absence of the deliberative character of this collegiate is emphasized as determined by the legislation that regulated it. The discussion brings elements for the reflection of social transformation through the participation of the subjects, proposing a dialogical and participatory process that does not depend exclusively on laws, but which, above all, is articulated with the purpose of realizing the ideals of a more just society, starting from more horizontal relations. We believe that the absence of deliberative character may interfere with the strategies of democratic management, leading to the belief that it de-characterizes the conception of participation in its broadest sense, giving rise to a more similar form of participationism.

Keywords: Democratic management; School councils; Participation.

\section{Introdução}

[...]São vidas que alimentam nosso fogo da esperança O grito da batalha Quem espera, nunca alcança[...] Gonzaguinha,1980.

Ao completar trinta anos de sua promulgação, a Constituição Federal (BRASIL, 1988) definiu a gestão democrática no âmbito das escolas públicas brasileiras como um princípio. Tal ordenamento ratifica o ideal de Estado Democrático de Direito, assegurando a participação popular, provocando uma horizontalização das relações e a partilha do poder. Era iminente a necessidade de debater, fomentar e estabelecer dispositivos legais, seguido de estratégias, voltados para que a gestão democrática pudesse ser legitimada e vivenciada pelos sujeitos no âmbito da escola pública.

O bojo destas necessidades pode ser compreendido à luz da epígrafe utilizada neste artigo, dado que a espera por uma democracia ideal - se é que ela existe - é ato minimamente ingênuo. Exemplo disto temos o período da promulgação da Carta 


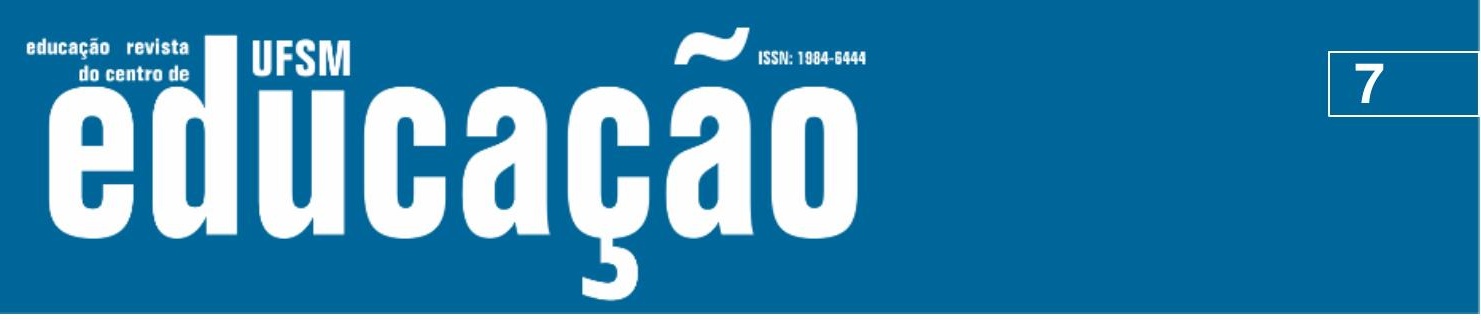

ISSN: 1984-6444 | http://dx.doi.org/10.5902/1984644436820

algo que precisa ser posto em relevo, dado os interesses e as partes interessadas que se apresentam para o debate (BALL, MAGUIRE, BRAUN, 2016).

A questão dos Conselhos Escolares na rede estadual do Rio de Janeiro tornouse um dos assuntos da pauta do movimento de greve dos profissionais da educação daquele estado, através do Sindicato dos Profissionais da Educação (SEPE). A greve iniciada em agosto de 2014 perdurou até outubro, quando o litígio entre SEPE/RJ e SEEDUC/RJ foi submetido à mediação do Supremo Tribunal Federal (STF), arrolado Medida Cautelar na Reclamação número 16.535/RJ (BRASIL, 2013), tendo como o relator da matéria o ministro Luiz Fux. Para efeitos de resolução do conflito estabelecido entre a Secretaria e o Sindicato naquele momento e visando o fim da greve, ficou definido que a SEEDUC publicaria o ato de criação (Decreto ou Lei) normatizando os conselhos escolares na rede no prazo de 90 dias a partir da data daquela reunião, se comprometendo a implementar tais organismos colegiados no prazo de um ano a contar da data de publicação do aludido ato criador (STF, 2013).

Seis meses depois, em 06 de maio de 2014, o governador do estado assinou o Decreto no 44.773 (RIO DE JANEIRO, 2014) criando os Conselhos Escolares nos estabelecimentos de ensino do estado do Rio de Janeiro com as funções consultiva, propositiva, mobilizadora e fiscalizadora, porém, não deliberativa. Este aspecto vai negligenciar o que se encontra previsto no Caderno 1 produzido pelo MEC que determina a função deliberativa destes Conselhos que se pauta nas decisões

\begin{abstract}
sobre o projeto político-pedagógico e outros assuntos da escola, aprovam encaminhamentos de problemas, garantem a elaboração de normas internas e o cumprimento das normas dos sistemas de ensino e decidem sobre a organização e o funcionamento geral das escolas, propondo à direção as ações a serem desenvolvidas. Elaboram normas internas da escola sobre questões referentes ao seu funcionamento nos aspectos pedagógico, administrativo ou financeiro. (BRASIL, 2004a, p.41)
\end{abstract}

Destacamos que a ausência da função deliberativa esvazia em poder o colegiado tendo em vista a impossibilidade dos conselhos escolares se firmarem como espaço decisório garantidor das decisões tomadas pelo coletivo. Se o conselho escolar é entendido como espaço decisório, como explicar que as pessoas que ali decidem podem não terem essas decisões na cena da escola, seja pela negação da sua autonomia, seja pelo ato discricionário de um gestor? 


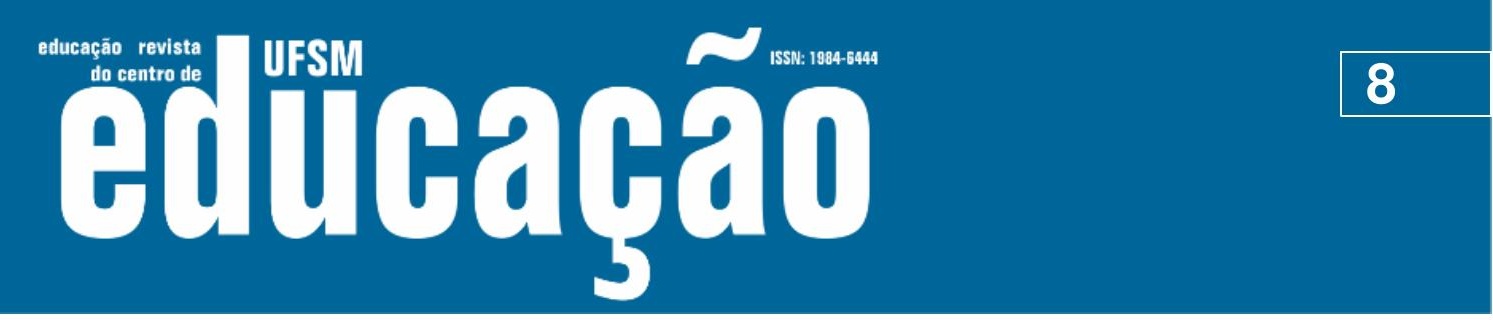

ISSN: 1984-6444 | http://dx.doi.org/10.5902/1984644436820

Ainda no artigo $5^{\circ}$ do Decreto 44.773, ficou estabelecido que caberia à Secretaria de Educação regulamentar, por meio de Resolução, o funcionamento dos Conselhos Escolares o que ocorreu no dia 30 daquele mesmo mês e ano. A Portaria SEEDUC/SUGEN no 485 (RIO DE JANEIRO, 2014b) estabeleceu procedimentos para a realização da consulta à comunidade escolar para a escolha dos membros, assim como no anexo I do referido documento ficou definido em quais Unidades Escolares se realizariam a consulta. Fato que contrariou o princípio de isonomia e contradiz o texto do próprio Decreto, assinado pelo governador. Prevista para ocorrer no último quadrimestre de 2014, a consulta entrou em cena em 144 escolas estaduais, representando, à época, pouco mais de $10 \%$ do total de escolas do estado. Apenas em maio de 2015, através da normatização da Portaria SEEDUC/SUGEN no 529 (RIO DE JANEIRO, 2015) que todas as escolas da rede passaram a contar com o conselho escolar instituído.

De acordo com a legislação da SEEDUC (RIO DE JANEIRO, 2014a), o Conselho Escolar é um organismo colegiado com funções previamente estabelecidas e aqui já mencionadas (Art. $3^{\circ}$ da Resolução). Segundo a mesma Resolução, são considerados membros da Comunidade Escolar:

I- os servidores membros do magistério público lotados na unidade escolar,
onde o conjunto destes servidores é denominado segmento professor;
II- os servidores membros do quadro administrativo educacional da
SEEDUC lotados na unidade escolar, onde o conjunto destes servidores é
denominado segmento funcionários administrativos;
III- alunos efetivamente matriculados na unidade escolar, onde o conjunto dos
alunos é denominado segmento aluno;
IV- pais ou responsáveis de alunos efetivamente matriculados na unidade
escolar, onde o conjunto deles é denominado segmento responsáveis.(RIO
DE JANEIRO, 2014a).

Nesse cenário de participação, indagamos para que serve um Conselho Escolar na escola? O que fazem estas pessoas pela escola? De que maneira isso pode melhorar a escola, a sala de aula, os processos de ensino e de aprendizagem? De que forma a atuação dos Conselhos Escolares pode assegurar a gestão democráticaii da/na escola? É nesse sentido que discutimos a prescritibilidade das normativas impostas pela Secretaria e a ausência do caráter deliberativo do Conselho Escolar nos textos oficiais daquela Secretaria. 


\section{ussm Autoabat}

ISSN: 1984-6444 | http://dx.doi.org/10.5902/1984644436820

educação se constituíram em contexto de influência bem como em contexto da prática da política por se fazerem presentes na escola, diariamente, colocando em cena a política de instituição dos conselhos escolares.

Os organismos colegiados ocupam preponderante papel no que tange à demarcação de um território que, por natureza da sua existência, exige, ainda que de forma tímida, certa prestação de contas dos assuntos de interesse coletivo. Não se trata de um accountability no sentido literal, porém, tem a ver com o papel representativo dos coletivos da/na escola que os conselhos escolares exercem. Portanto, é salutar questionar com qual frequência e com que arcabouço de informações os atores pertencentes a este colegiado se posicionam no jogo democrático.

Destarte, torna-se pertinente apresentar e analisar as diferenças existentes entre desconcentração e descentralização, estabelecendo uma costura com as funções dos Conselhos Escolares e as correlações e relevâncias para a gestão democrática. Estas análises contribuem para embasar as críticas aqui expostas acerca da prescritibilidade dos textos oficiais escritos pela SEEDUC/RJ para a normatização dos referidos organismos colegiados.

\section{Desconcentração $x$ descentralização: qual face da gestão democrática para os conselhos escolares?}

Arruda (2014) ressalta que pensar historicamente o papel político dos conselhos na administração pública brasileira nos ajuda a compreender as contradições e os desafios postos aos conselhos escolares contemporâneos e à gestão democrática. A autora destaca que estes não operam no vácuo, eles são frutos da sociedade brasileira e dialogam com o amadurecimento de nosso processo democrático.

Diante disto, é pertinente pensar para qual face da gestão democrática na escola e para a escola os conselhos escolares estariam a serviço. Pensando no seu papel político e descentralizador, demandando, deliberando, estabelecendo conexões e interdependência com outros organismos colegiados ou se estaria mais voltado para 


\section{N-Tis

ISSN: 1984-6444 | http://dx.doi.org/10.5902/1984644436820

um modelo burocrático, cartorial, configurando-se como componente ilustrativo em um desenho de desconcentração da gestão. Em relação à descentralização, cabe ressaltar que o papel deliberativo de um conselho escolar legitima seu caráter político, autônomo e democrático. Também reafirma a sua identidade ativa e política no contexto das relações de horizontalidade na cena democrática da/na escola pública.

A horizontalidade da gestão se assemelha mais ao modelo de descentralização, uma vez que implica, sobretudo, na partilha do poder e das decisões tomadas. Cabe ressaltar que Arruda (2014, p.118) chama atenção para a cena contemporânea que amálgama os conselhos escolares quando afirma que "[...] os conselhos chegam à contemporaneidade trazendo em si uma contradição - sua origem que os vincula como expressão de fortalecimento do poder de um grupo social -, e sua posterior incorporação, pela esquerda, como forma de organização popular".

Diante disso, a descentralização pode ser entendida como uma espécie de imunização aos grupos de interesses que se serviam deste caráter para fortalecer seus pares, defender interesses nem sempre voltados para o coletivo, e, consequentemente, não discutidos em prol de um bem de todos. No cenário atual, o binômio descentralização-desconcentração aponta para nuances semelhantes aos interesses subjetivos daquele momento mencionado pela autora. Sob a definição de Antunes (2002, pp.96-97), apresentamos no quadro 1 uma proposta comparativa entre desconcentração e descentralização. 


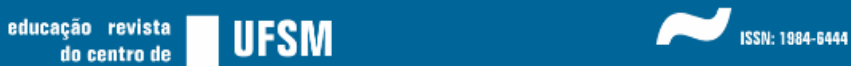 Fillbap̧a}

ISSN: 1984-6444 | http://dx.doi.org/10.5902/1984644436820

Quadro 1: Comparativo entre Desconcentração e Descentralização

\begin{tabular}{|l|l|}
\hline \multicolumn{1}{|c|}{ DESCONCENTRAÇÃo } & \multicolumn{1}{|c|}{ DESCENTRALIZAÇÃo } \\
\hline $\begin{array}{l}\text { Mudanças que levam em conta uma } \\
\text { dispersão físico-territorial das agências } \\
\text { governamentais que até então estavam } \\
\text { localizadas centralmente e maior divisão } \\
\text { de tarefas. }\end{array}$ & $\begin{array}{l}\text { Não significa só dispersão físico-territorial das } \\
\text { agências governamentais, ou maior divisão de } \\
\text { tarefas, mas descentralização } \\
\text { (divisão/distribuição) do poder. }\end{array}$ \\
\hline $\begin{array}{l}\text { Não ameaça as estruturas administrativas } \\
\text { consolidadas. }\end{array}$ & $\begin{array}{l}\text { Envolve profunda modificação nas estruturas } \\
\text { administrativas. }\end{array}$ \\
\hline $\begin{array}{l}\text { Continua a subordinação política, técnica } \\
\text { e financeira de estados e municípios } \\
\text { diante do governo federal. }\end{array}$ & $\begin{array}{l}\text { Implica transferência de poderes do nível } \\
\text { central para o nível local. }\end{array}$ \\
\hline $\begin{array}{l}\text { Reparte encargos e serviços e delega } \\
\text { funções. }\end{array}$ & $\begin{array}{l}\text { Reparte opções e decisões, reconhece } \\
\text { direitos e atribui responsabilidades. }\end{array}$ \\
\hline $\begin{array}{l}\text { É um processo cujo objetivo é assegurar } \\
\text { a eficiência do poder central, refletindo um } \\
\text { movimento "de cima para baixo". }\end{array}$ & $\begin{array}{l}\text { É um processo que procura assegurar a } \\
\text { eficiência do poder local, refletindo um } \\
\text { movimento "de baixo para cima". }\end{array}$ \\
\hline $\begin{array}{l}\text { Não conta com mecanismos de controle } \\
\text { social e transparência no processo } \\
\text { decisório. }\end{array}$ & $\begin{array}{l}\text { Abre portas do Estado à participação da } \\
\text { população organizada, criando mecanismos } \\
\text { político-institucionais de articulação, canais } \\
\text { orgânicos de comunicação constante, } \\
\text { aceitando as pressões daí advindas. }\end{array}$ \\
\hline
\end{tabular}

Fonte: ANTUNES (2002, pp.96 - 97).

As definições propostas pela autora entre os mecanismos e características da desconcentração e da descentralização no âmbito da gestão da coisa pública auxiliarão na compreensão dos argumentos propostos neste artigo destinados a analisar, a partir dos textos oficiais escritos pela SEEDUC/RJ, o tipo de engajamento e entendimento dos atores acerca da gestão democrática da escola estendendo esta compreensão aos conselhos escolares, concebido como importante mecanismo da democracia neste espaço.

Em 2015, a rede estadual fluminense contava com 1290 Conselhos Escolares instituídos, levando em consideração que possuía sob sua abrangência 1308 Unidades Escolares de acordo com dados disponíveis no portal eletrônico QEdu (2018). A Resolução 5.109 (RIO DE JANEIRO, 2014a) foi o texto oficial responsável 


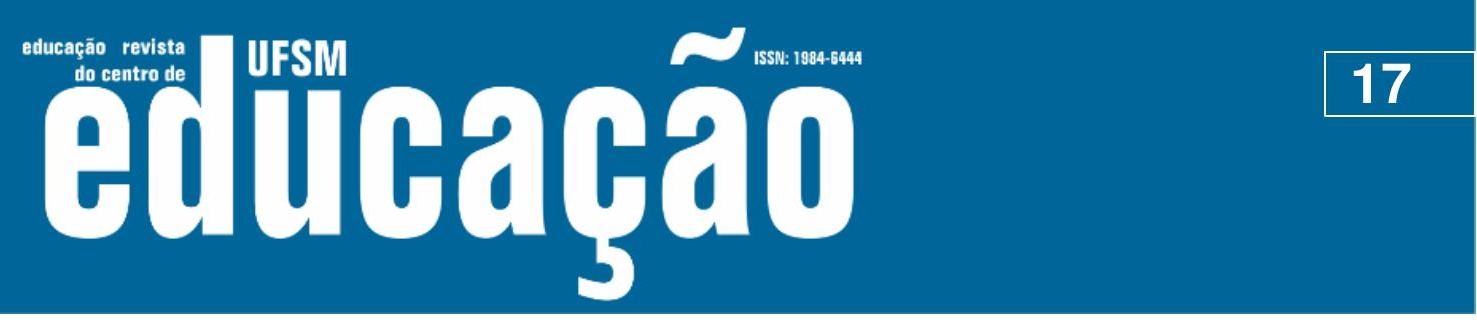

ISSN: 1984-6444 | http://dx.doi.org/10.5902/1984644436820

O conceito de participação fundamenta-se no princípio da autonomia, que significa a capacidade das pessoas e dos grupos para a livre determinação de si próprios, isto é, para a condução da própria vida. Como a autonomia se opõe às formas autoritárias de tomada de decisão, sua realização concreta nas instituições dá-se pela participação na livre escolha de objetivos e processos de trabalho e na construção conjunta do ambiente de trabalho.

Podemos pensar que os Conselhos Escolares da rede estadual do Rio de Janeiro estariam mais assemelhados aos moldes da desconcentração proposto por Antunes (2002). Diante disso, a relativização da autonomia dos Conselhos seria outro ponto importante para 0 debate da gestão democrática, nos cabendo indagar: democrático para quem? Até que ponto? Para qual compreensão de democracia?

Na perspectiva do texto produzido pela Secretaria de Educação, o litígio entre SEPE e SEEDUC passa a ser sobre a instituição dos Conselhos Escolares nas escolas da rede e não sobre o teor da escrita do texto oficial em si, configurando-se no que poderíamos chamar de contexto da prática. Até então, compreendeu-se que o processo de disputa apontava para a vitória do sindicato, uma vez que, partindo da premissa de que o estabelecimento destes organismos colegiados se apresentava como um avanço, um caminho ainda a ser pavimentado na concepção de uma gestão democrática, os engessamentos e as prescritibilidades que poderiam haver na escrita estavam encobertos pela ilusão de que a participação seria algo dado e não algo a ser conquistado.

Não queremos descredenciar os avanços e a conquista da categoria. Essa luta tem potente força e também se apresentou como outras configurações de contextos de influência na cena política do estado do Rio de Janeiro. O que queremos sublinhar é que a política de atuação precisa ser repensada e encarada como luta constante, pois assim como não somos os mesmos com o passar do tempo, a cena social, econômica e política se reconfigura e se apensam a outros modos de entender, atuar e viver as políticas. Tal como as fases do ciclo da política estão aninhadas, a vida em sociedade é um constante 'vir a ser' e transformar. As análises propostas emergem do entendimento que relativizam não só a participação, mas também a legitimidade da autonomia dos sujeitos deste organismo colegiado.

Nos obriga, nesse sentido, a pensar se há um exercício em defesa dos interesses dos coletivos existentes na escola ou se está muito mais voltado para o 


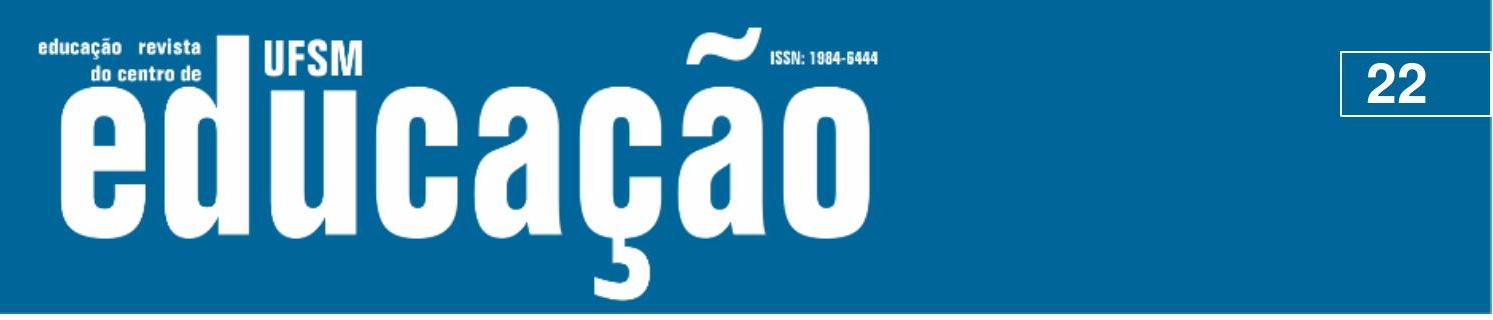

ISSN: 1984-6444 | http://dx.doi.org/10.5902/1984644436820

LIMA, Licínio C. Entrevista concedida ao Jornal do Comércio. Notícia da edição impressa de 12/04/2017. - Jornal do Comércio Disponível em: https://www.jornaldocomercio.com/_conteudo/2017/04/geral/556931-nao-haeducacao-que-nao-seja-politica--diz-licinio-lima.html. Acesso em: 02 jan. 2019.

LIMA, Licínio C. Por que é tão difícil democratizar a gestão da escola pública? Educar em Revista. Curitiba. V.34, n.68, p.15/28, mar./abr.2018.

MAINARDES, J. A abordagem do ciclo de políticas: explorando alguns desafios da sua utilização no campo da Política Educacional. Jornal de Políticas Educacionais. V. 12, n. 16. Agosto de 2018. ISSN 1981-1969.

MENDONÇA, Erasto Fortes Estado patrimonial e gestão democrática do ensino público no Brasil. Educação e Sociedade. 2001, vol.22, n.75, pp.84-108. ISSN 01017330.

QEdu. Disponível em: http://www.qedu.org.br/estado/119-rio-de-janeiro/censoescolar?year $=2015 \&$ localization $=0 \&$ dependence $=0$ \&education_stage $=0$ \&item $=$ matric ulas. Acesso em, 07 jul. 2018.

RIO DE JANEIRO. Decreto ${ }^{\circ}$ 44.773, de 06 de maio de 2014. Cria os Conselhos Escolares nos Estabelecimentos de Ensino de Educação Básica da Rede Pública Estadual do Rio de Janeiro. Rio de Janeiro, RJ, 2014.

RIO DE JANEIRO. Resolução 5.109, de 30 de maio de 2014. Estabelece Diretrizes para criação, instalação e funcionamento dos Conselhos Escolares nos Estabelecimentos de Ensino da Rede Pública Estadual e dá outras providências. Rio de Janeiro, RJ, 2014a.

RIO DE JANEIRO. Constituição do Estado do Rio de Janeiro. Disponível em: file://C:/Users/draja/AppData/Local/Packages/Microsoft.MicrosoftEdge_8wekyb3d8b bwe/TempState/Downloads/Constituição\%20estadual.pdf. Acesso em: 03 ago. 2018.

RIO DE JANEIRO. Portaria SEEDUC/SUGEN no 485 de 30 DE JULHO DE 2014. Estabelece procedimentos para a realização da consulta à comunidade escolar para escolha dos membros dos Conselhos Escolares nos Estabelecimentos de Ensino da Secretaria de Estado de Educação do Rio de Janeiro e dá outras providências. Rio de Janeiro, RJ, 2014b.

RIO DE JANEIRO. Portaria SEEDUC/SUGEN no 529, de 24 de março de 2015. Estabelece procedimentos para a realização da consulta à comunidade escolar para escolha dos membros dos Conselhos Escolares nos Estabelecimentos de Ensino da Secretaria de Estado de Educação do Rio de Janeiro, e dá outras providências. Rio de Janeiro, RJ, 2015.

RIO DE JANEIRO. Projeto de Lei no 1910/2016. Disponível em: http://alerjln1.alerj.rj.gov.br/scpro1519.nsf/18c1dd68f96be3e7832566ec0018d833/06 8309 ecfd19f57883257fd4006cac68?OpenDocument\&Start=1.1.1.3. Acesso em: 03 ago. 2018. 


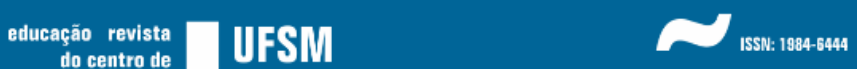

ISSN: 1984-6444 | http://dx.doi.org/10.5902/1984644436820

SILVA, Maria Adeilza da. Os colegiados e a gestão escolar no RN: experiências dos gestores. XXVI Simpósio Brasileiro de Política e Administração da Educação. Recife, PE, 2013.

SOUZA, Ângelo Ricardo de. Explorando e construindo um conceito de gestão escolar democrática. Educação em Revista. Belo Horizonte: UFMG, v.25; n.03; p.123-140, dez. 2009.

TRAGTENBERG, Mauricio. Administração, poder e ideologia. 3a São Paulo: UNESP, 2005.

UGARTE, Pedro Salazar. Que participação para qual democracia. In: COELHO, Vera Schattan; NOBRE, Marcos (orgs.). Participação de deliberação: Teoria democrática e experiências institucionais no Brasil Contemporâneo. São Paulo: Ed. 34, 2004.

\section{Correspondência}

Janaina Moreira de Oliveira Goulart - Universidade Federal do Rio de Janeiro - Av. Pedro Calmon. № 550 - Cidade Universitária - CEP 21941-901. Rio de Janeiro, RJ, Brasil.

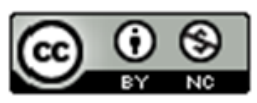

This work is licensed under a Creative Commons Attribution-NonCommercial 4.0 International (CC BY-NC 4.0)

\footnotetext{
' Conforme Formosinho (2009) a escola de massa é essencialmente heterogênea, seja do ponto de vista dos professores, seja do ponto de vista dos alunos e do contexto geográfico e social de inserção das escolas. Utilizamos o conceito escola de massas para indicar a intervenção do Estado na educação escolar tornando-a obrigatória, gratuita e universal.

ii Com base em Souza (2009) compreendemos a gestão democrática como um processo político no qual as pessoas que atuam na/sobre a escola identificam problemas, discutem, deliberam e planejam, encaminham, acompanham e avaliam o conjunto das ações voltadas ao desenvolvimento da própria escola na busca da solução daqueles problemas.
} 